\title{
AUTOMATED CONSTRUCTION OF UNDERGROUND TANK
}

\author{
H.AOKI \\ PLANT CONSTRUCTION DEPARTMENT \\ TOKYO GAS CO., LTD \\ NO.34 SHINISOGO-CHO, ISOGO-KU, YOKOHAMA-SHI, KANAGAWA 235, JAPAN \\ Y.TSUKAHARA, Y.KAJIOKA, and T.ODAWARA \\ MACHINERY DEVELOPMENT DEPARTMENT \\ TECHNOLOGY DIVISION \\ SHIMIZU CORPORATION \\ N0.2-3, SHIBAURA 1-CHOME, MINATO-KU, TOKYO 105-07, JAPAN \\ K.KUBOTA, Y.TANAKA, K.SUZUKI, A.KAIYA, and M.SUNAHARA \\ CIVIL ENGINEERING DEPARTMENT \\ CIVIL ENGINEERING DIVISION \\ SHIMIZU CORPORATION \\ NO.34 SHINISOGO-CHO, ISOGO-KU, YOKOHAMA-SHI, KANAGAWA 235, JAPAN
}

\begin{abstract}
An automated landslide protection wall construction system and an automated concrete placing system were developed and applied in an underground LNG tank construction project at the Negishi plant of Tokyo Gas. The underground LNG tank is a huge vertical shaft storage of liquefied natural gas. This tank is a concrete structure of internally cylindrical shape lined on the inside with thermal insulation material and membrane. The structure has an inside diameter of $50 \mathrm{~m}$ and depth of approximately $40 \mathrm{~m}$.

Conventionally, landslide protection work and concrete placing work entailed in construction of an underground tank have involved operations in adverse environments of great height, dirtiness, noisiness, etc., and have required much effort for improvement of productivity and quality.

The landslide protection work automation system introduced for this project is composed of a "Mesh Setter" equipped with a nailing machine for anchoring reinforcing mesh and a mesh anchoring apparatus which automatically positions and fixes mesh at a wall surface, a "Gunite Shooter" which pneumatically applies mortar to the wall surface moving a revolving nozzle up and down, right and left, and further, a "Rock Bolt Setter" which automatically performs a series of operations consisting of drilling holes in the reinforced, mortar-lined walls, injecting grout in the holes, and inserting rock bolts in the holes.

The automated concrete placing system comprises an "Automatic Placing Apparatus" capable of placing concrete to a uniform height at a concrete side wall, an "Compaction Robot" which automatically compacts the concrete placed, and a "Placing Management System" which manages concrete placing operations in timely fashion to allow work to be done more smoothly.

The number of workers required has been reduced to less than one-third compared with before, while the working environment has been improved through adoption of these systems.
\end{abstract}

\section{INTRODUCTION}

An underground tank construction project consists of excavating the ground cylindrically and placing concrete at the bottom and side walls to build a tank of reinforced concrete. (See Fig.1)

The authors' company has been engaged in development work aiming for automation and mechanization of the various steps shown in Fig.2 with the objective of improving productivity of underground tank construction. 


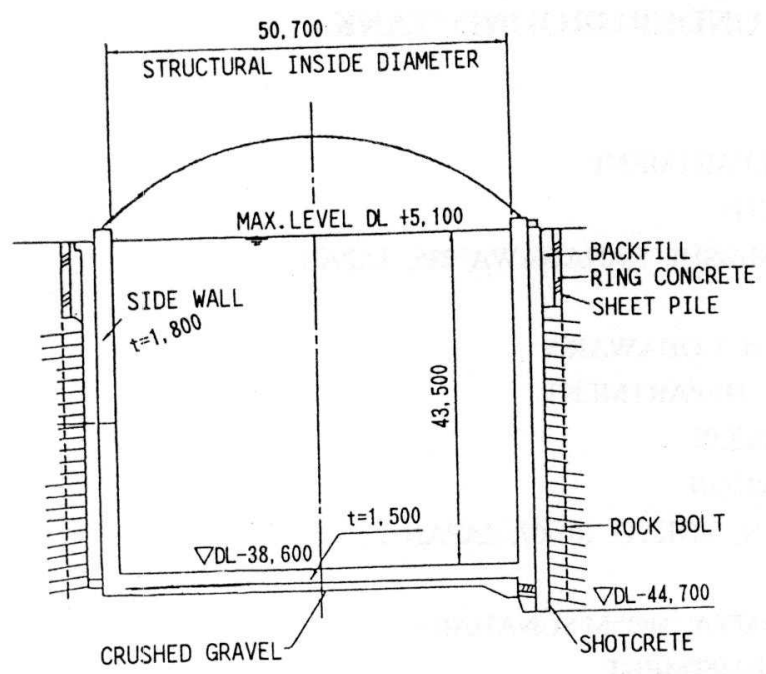

Fig.1 LNG STORAGE TANK (CROSS-SECTION)

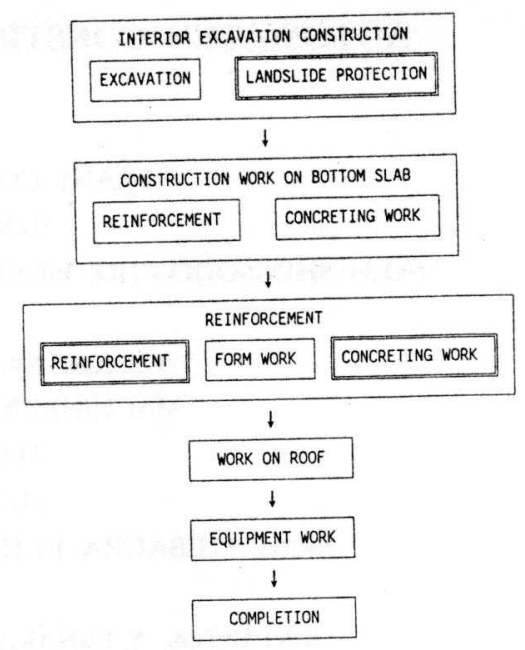

Fig.2 PROCEDURE FOR LNG STORAGE TANK CONSTRUCTION

This paper describes the landslide protection work automated execution system used for "Landslide Protection Work" entailed in internal excavation, and the side wall concrete automatic placing system used in "Concrete Placing Work" in side wall concreting.

\section{AUTOMATED LANDSLIDE PROTECTION WORK SYSTEM}

The landslide protection work automation system is for application in landslide protection work accompanying excavation of hardpan, and the system is centered on the three special robots for performing the series of work consisting of "stretching of mesh" $\rightarrow$ "gunite shoot" $\rightarrow$ "driving in of rock bolt". Conventionally, these operations have been carried out by about 30 people working manually or directly operating machines, and the work was performed under adverse conditions such as heavy dusting, and productivity was not good.

\subsection{Composition of System and Implementation}

The landslide protection work is performed with the three kinds of robots of Mesh Setter, Gunite Shooter, and Rock Bolt Setter. Special rails are installed from the top of the excavation at the inner side of the tank, and the various robots are suspended along the wall surface in gondola fashion by means of trolleys running on the rails.

The excavation work is done one level of $1.5 \mathrm{~m}$ at a time while carrying out earch retaining work.

Landslide protection work is done using in order "Mesh Setter" $\rightarrow$ "Gunite Shooter" $\rightarrow$ "Rock Bolt Setter", and the individual robots going around performing work on the excavated wall height of approximately $1.5 \mathrm{~m}$ corresponds to completion of a single level. The capacities of the robots were set so that one level of landslide protection work can be performed in 3 days. The functions and constructions of the individual robots are described below, while Fig.3 shows in outline the landslide protection works by the three different robots.

\section{(1) Mesh Setter}

A mesh loaded horizontally on the bottom part of the frame of the robot proper is held magnetically, and rotating the mesh parallel to the excavated wall surface, it is attached to the wall surface, upon which moving is done laterally to the next work position. Mesh of $1.7 \mathrm{~m}$ longitudinally and $2.0 \mathrm{~m}$ transversely can be set at a rate of $9\left(30 \mathrm{~m}^{2}\right) / \mathrm{h}$. 

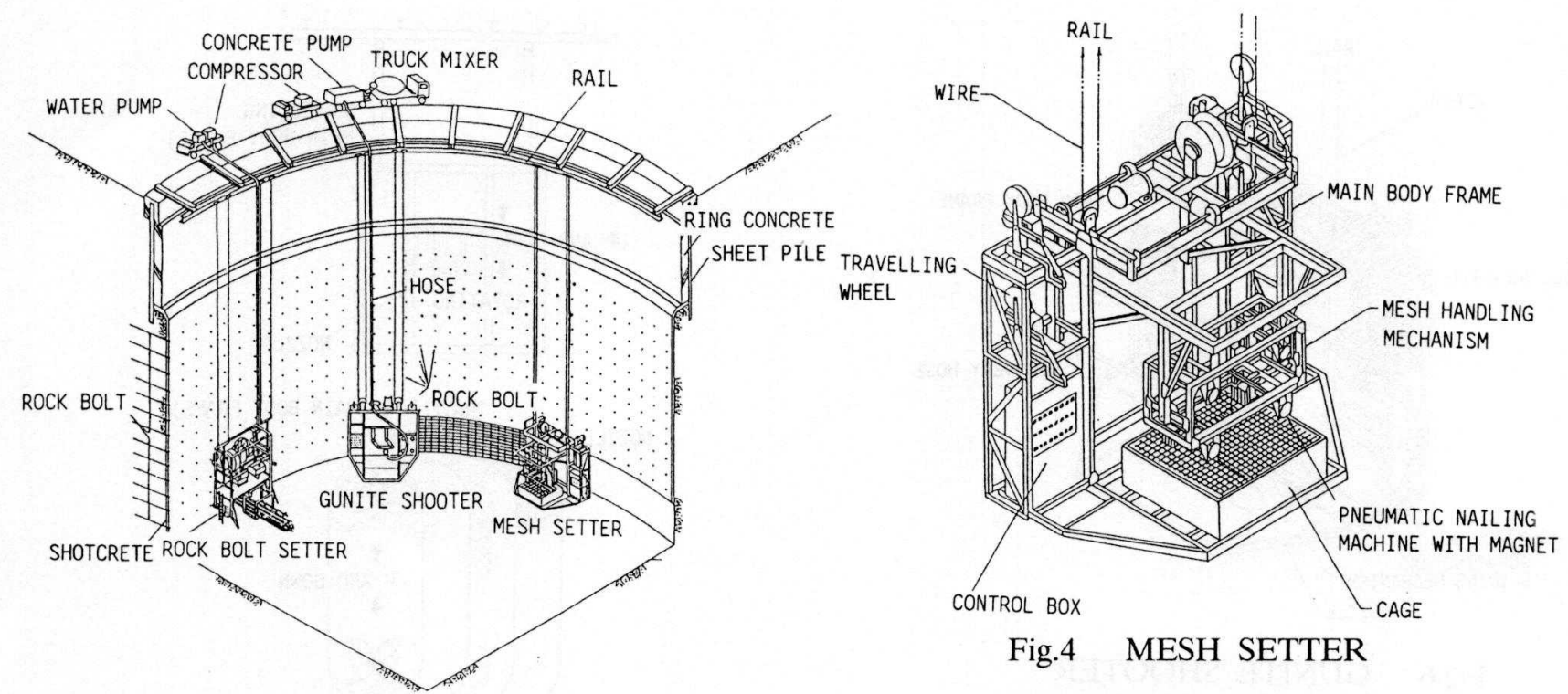

Fig.4 MESH SETTER

\section{Fig.3 AUTOMATED LANDSLIDE PROTECTION WORK}

Fig.4 shows the construction of the Mesh Setter in outline, and Fig.5 the procedure for setting mesh.

The mesh holder section has a pneumatic type nail driver and an electromagnet at the end of an electricdrive cylinder and four of these holders are set in a box-shaped frame capable of rotating and sliding.

Fixing hardware attached to the mesh is used, and extending the electricdrive cylinder in a condition of mesh held by magnet, the mesh is pushed against the wall surface, upon which the nail driver acts automatically to fix the mesh to the wall.

\section{(2) Gunite Shooter}
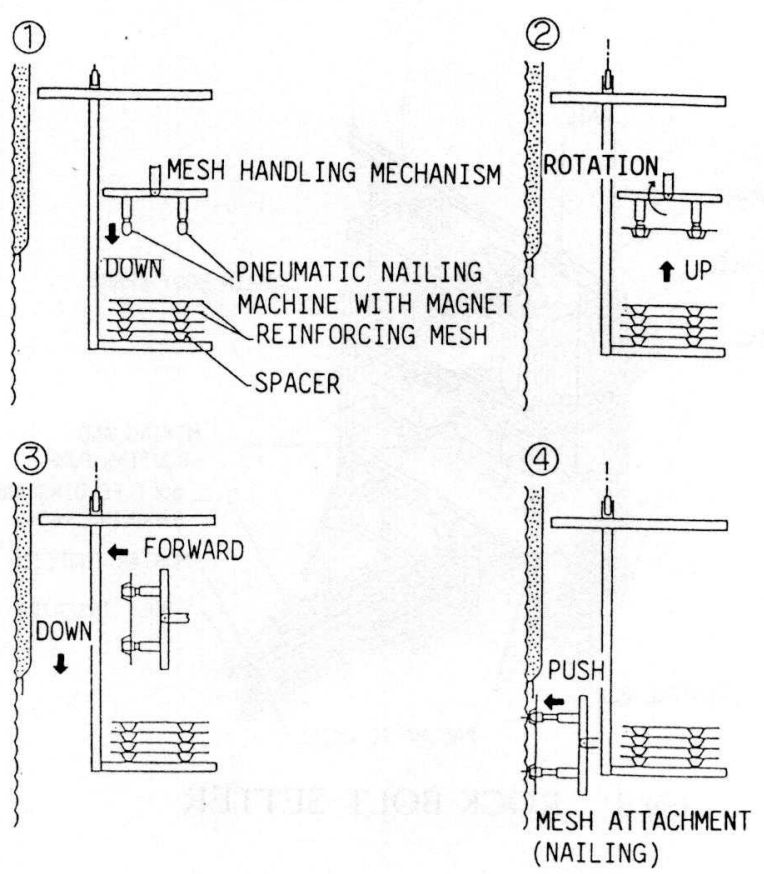

Fig.5 SEQUENCE OF ATTACHED MESH TO MESH SETTER

The gunite shooting action consists of a nozzle made to move up and down inside the main body frame while rotating, and a given distance is automatically travelled sideways with each up-and-down movement of the nozzle. The diameter of the rotating movement of the nozzle can be adjusted between 30 and $60 \mathrm{~cm}$, the rotating speed betweem 0 and $40 \mathrm{rpm}$, the ascent-descent stroke between 0 and $2.0 \mathrm{~m}$, shooting distance between 1 and $2.5 \mathrm{~m}$, and the nozzle angle between plus and minus $15 \mathrm{deg}$.

The supply of material is carried out by a concrete pump installed above ground. Mortar delivered by the pump through hose is shot from a nozzle together with a flash-setting agent and compressed air. The amount of mortar supplied is $5 \mathrm{~m}^{3} / \mathrm{h}$, and the rate of application is about $30 \mathrm{~m}^{3} / \mathrm{h}$.

The construction of the Gunite Shooter is shown in Fig.6, and an outline of the application procedure in Fig.7. 


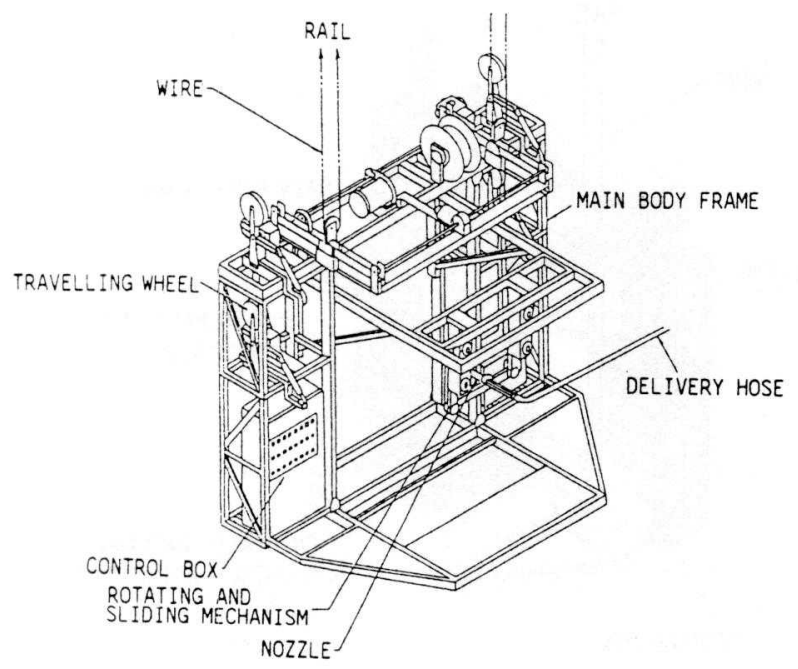

Fig.6 GUNITE SHOOTER

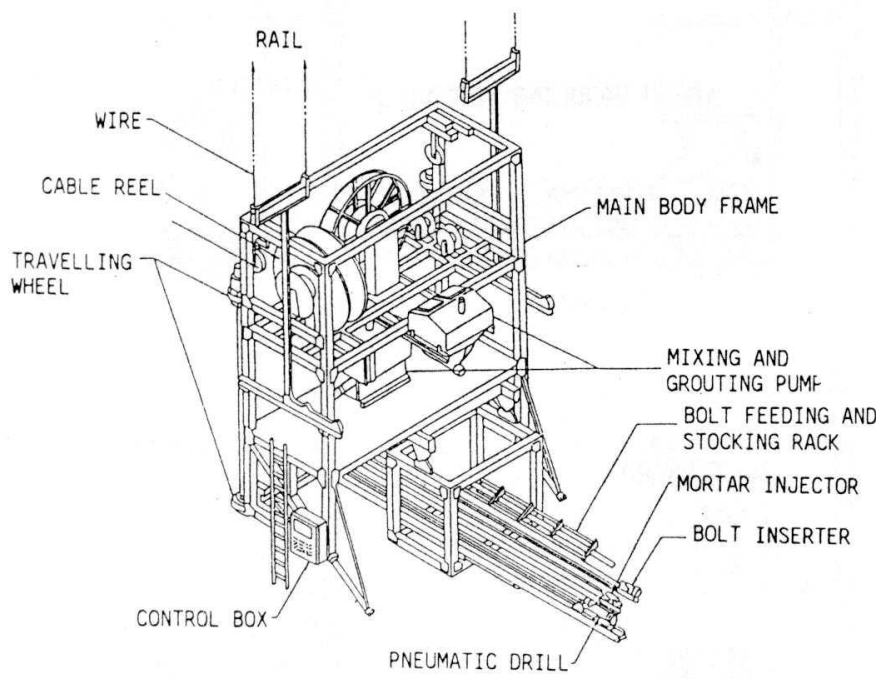

Fig.8 ROCK BOLT SETTER
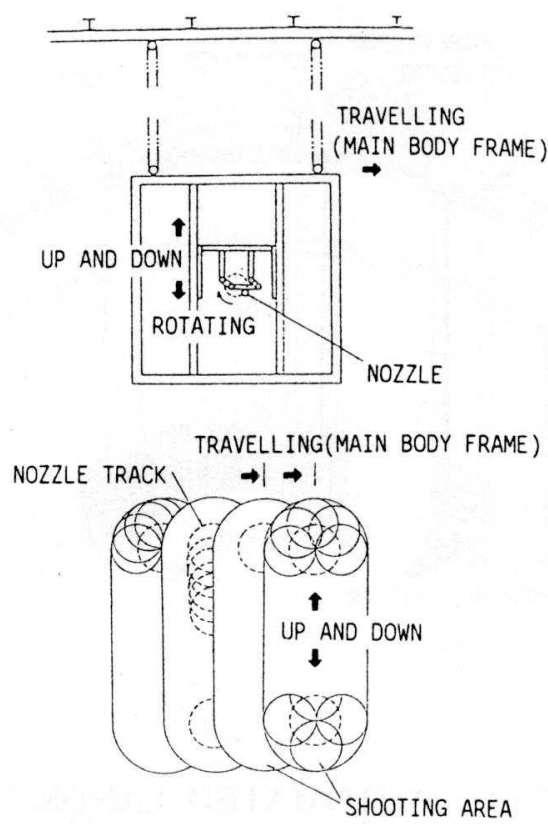

Fig.7 SEQUENCE OF SHOOTING WITH GUNITE SHOOTER
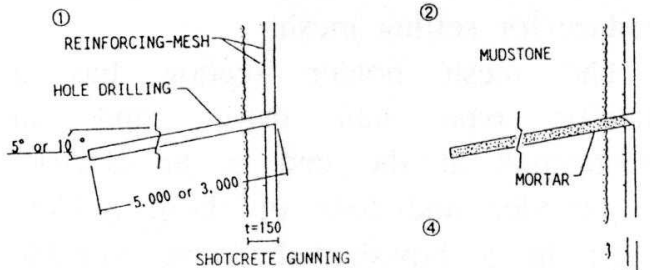

(4)

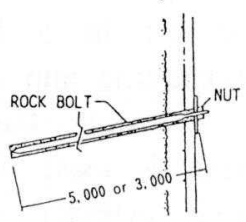

Fig.9 SEQUENCE OF INSTALLING ROCK BOLTS

\section{(3) Rock Bolt Setter}

The frame of the robot proper contains a drill, mortar mixing apparatus, mortar injector, bolt inserter, and bolt stocking rack.

The work begins with drilling a hole from on top of the mortar wall surface with a drill (compressed air type drifter), inserting the injection pipe of the mortar injector in the hole and filling the hole with mortar while withdrawing the pipe. A rock bolt is inserted by means of the bolt inserter. After completing this series of operations, the setter moves laterally by means of the trolley and the driving wheel of the setter proper to go on to the next work position. It is possible for 50 rock bolts to be carried on the stocking rack of the robot, and 12 bolts can be installed in one hour. The construction of the rock bolt setter is shown in outline in Fig.8, and the approximate operations procedure for installing rock bolts in Fig.9.

Supply of mortar for fixing is by a mini-plant system stocking premixed mortar in the robot proper and mixing and pumping from the setter proper. The only manual work done is introducing premixed mortar to the stock bin. 


\subsection{Features of Operations by Robots}

- Since the robots proper are suspended in gondola fashion, operations can be performed without being influenced by the condition of excavation and levelling of the bottom surface of the shaft.

- The number of workers can be reduced as the series of operations can be done automatically.

- Because there is no direct manipulation of machinery by workers, operations can be carried out safely. Also, workers are released from operations under adverse conditions.

- The height of attachment of mesh, position of mortar application, position of hole drilling, etc. are maintained constant at all times, and work of high grade can be accomplished.

- Because of a suspended gondola system, work can be executed regardless of height, and it is possible for additional setting of bolts to be done after excavation has progressed. (Rock Bolt Setter)

\section{AUTOMATED CONCRETE PLACING SYSTEM}

The automated concrete placing system is applied to concrete placing work accompanying construction of side walls.

Concrete placing work is done dividing the whole circumference of the tank into four parts. Concrete is placed in lifts of $50 \mathrm{~cm}$ in concrete forms in which reinforcing bars have been assembled, taking up one whole hour at a time so that forms will not be damaged by lateral pressure of concrete. Compaction is achieved by vibrators.

The side walls are constructed repeating this work cycle several dozen times to place several thousand cubic meters of concrete of uniform finish. Conventionally, these operations have required about 60 people to do manual work or directly operate machines. The work had to be done in adverse environments involving hard labor at great heights, where quality control was difficult to implement, and productivity was poor.

\subsection{Composition of System and Implementation}

The automated placing system is composed of the three subsystem of "Automatic Placing Apparatus", "Compaction Robot", and "Placing Management System".

The Automatic Placing Apparatus has automatic valves installed on the side wall forms and an automatic valve control box above ground for accomplishing work. The Compaction Robot is used providing special rails at the inner side of the tank from which it is suspended in gondola fashion by means of a

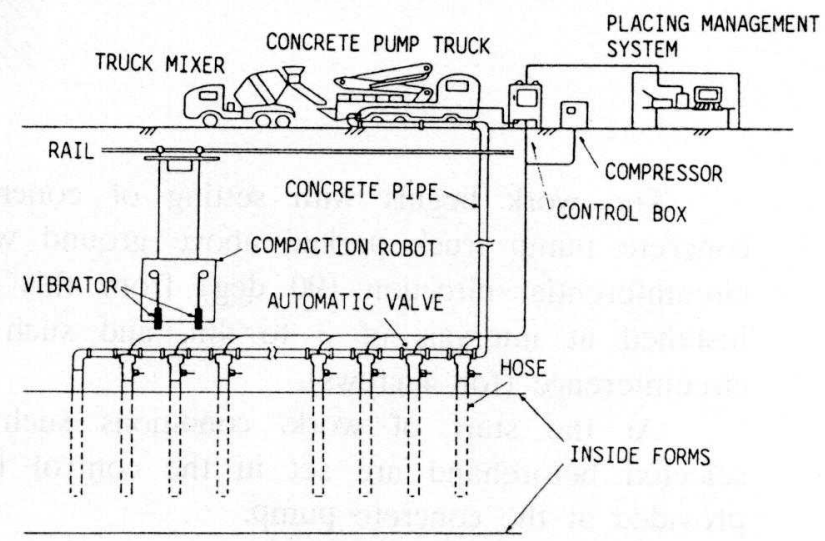

Fig.10 AUTOMATED CONCRETE PLACING SYSTEM trolley. The placing management system is installed above ground making it possible to have a grasp of the state of concrete placing from the top of the tank. The functions and compositions of the individual subsystem are described below with the constructions of the three subsystems shown in Fig.10.

\section{(1) Automatic Placing Apparatus}

This apparatus is composed of automatic valves and an automatic valve control Box. The automatic valves open and close with air cylinders reciprocated by compressed air from the air compressor located above ground. The automatic placing of concrete by the automatic opening and closing is performed using the automatic valve control box. 


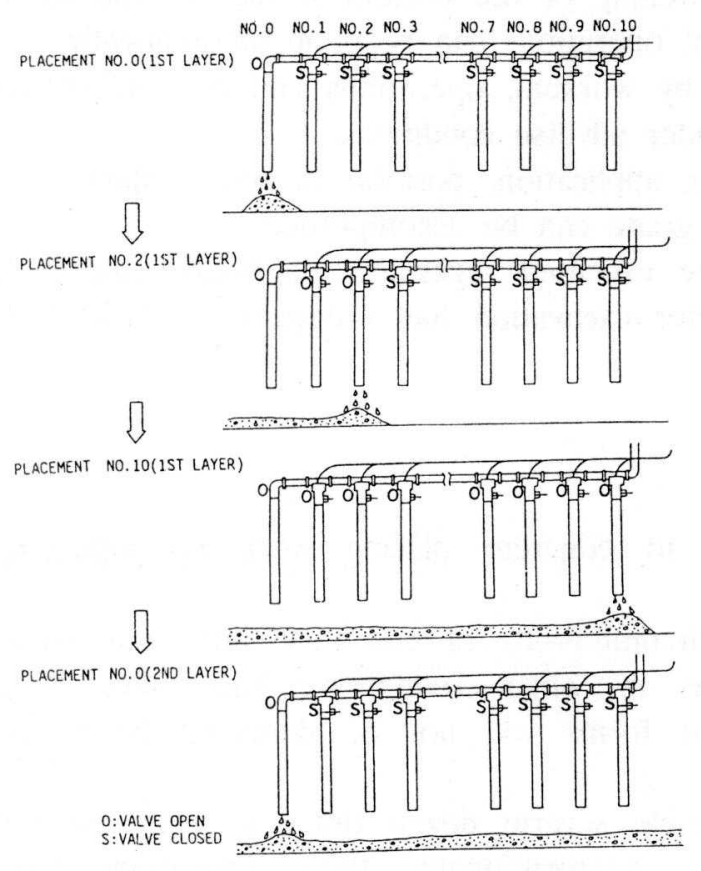

Fig.11 SEQUENCE OF CONCRETE PLACING
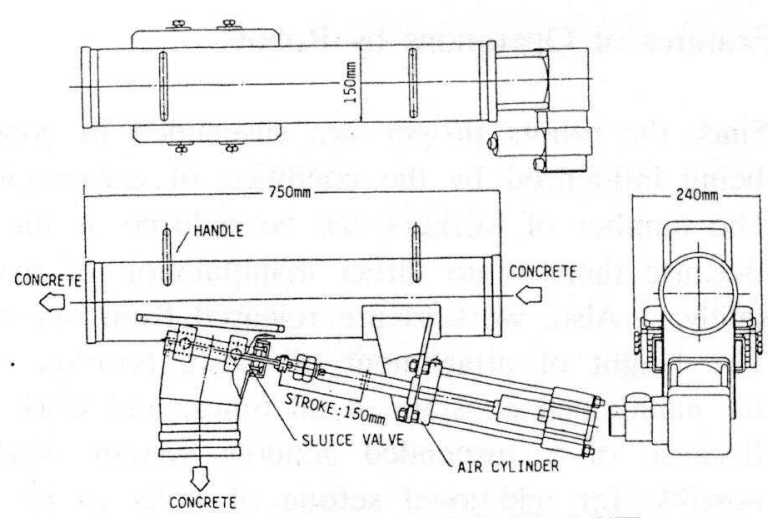

Fig.12 AUTOMATIC VALVE

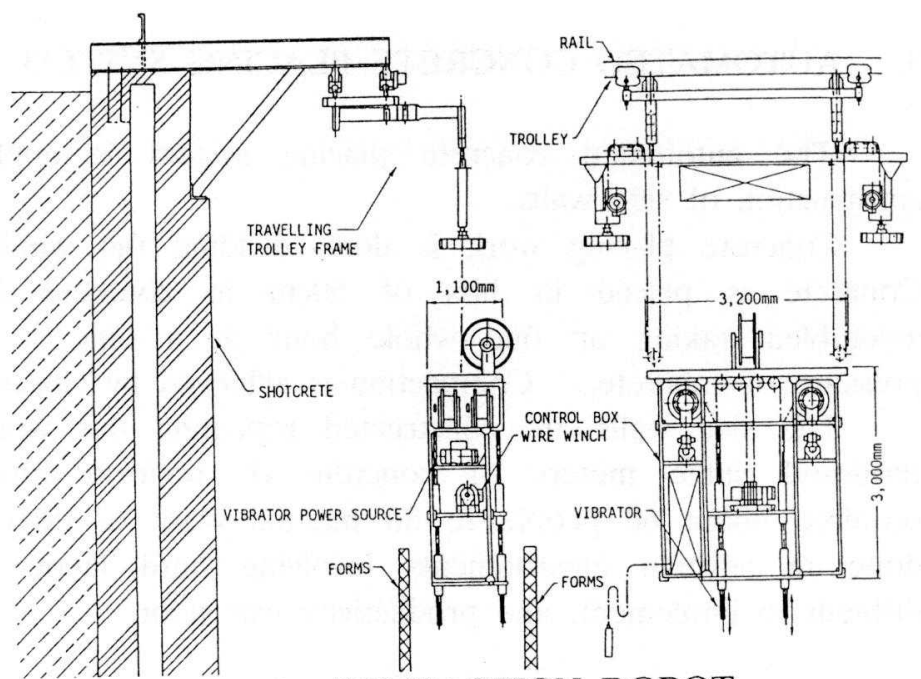

Fig.13 COMPACTION ROBOT

The work begins with setting of concrete pipe vertically along the wall surface from a concrete pump truck parked above ground with a concrete pipeline installed horizontally in the circumferential direction $(90 \mathrm{deg})$ from this vertical concrete pipe. Ten automatic valves are installed at intervals of 3 to $4 \mathrm{~m}$, and such sets of installation work are done for the entire circumference (for 4 crews).

At the start of work, conditions such as height of placing, height of placing lift, etc. selected beforehand are set in the control box, and a sensor for measuring placing volume is provided at the concrete pump.

When automatic operation is started and concrete is supplied from the concrete pump, the quantity of concrete is automatically measured while automatic placing is performed, and the operation is terminated on satisfying the requirements set up.

The operating procedure of an automatic valve during placing is shown in Fig.11, and an automatic valve proper in Fig.12.

\section{(2) Compaction Robot}

The robot is of box type having a steel frame in which four vibrators are accomodated. Four robots sre suspended in gondola fashion from rails set circumferentially at the inner periphery of the tank.

Each robot has one-fourth the circumference of the tank as its alloted range of placement. It stops each time it has travelled laterally about $2 \mathrm{~m}$, and the vibrators are inserted in the concrete to perfrom compaction. 
The vibrators which perfrom compaction are suspended by wires from a which in the robot proper and are lowered automatically from the robot proper to the surface of the placed concrete. That the vibrators have been inserted in the concrete is detected and the vibrators are stopped at a suitable height with vibration carried out for a given length of time, upon which the vibrators are returned to the original position to complete a round of work. This series of operations is repeated 20 times to complete work for one lift. (See Fig.13)

\section{(3) Placing Management System}

The system is composed of a personal computer (PC), a cathode ray tube (CRT), and a printer. The CRT is set to show three kinds of images, and the condition of concrete placing of the entire tank, the total volume of concrete placed, and the volumes placed and the states of progress of the individual crews can be supervised. Since the controller can switch images by the easy operation of the PC, information concerning the work being done is obtained in real time, and placement can be done as planned.

The information gathered concerning each crew is inputted to the PC in the forms of manages information of each automatic valve control box, with programming done for the information to be remade inside in the forms of supervision information.

The control information for the various images is shown in Fig.14-1, 2, 3.

3.2 Features of Operations by Individual Systems

- The series of operations for concrete placing and consolidation are automated, and the number of workers conventionally required of about 60 people can be lowered to less than one-fourth, and manpower requirements can be reduced.

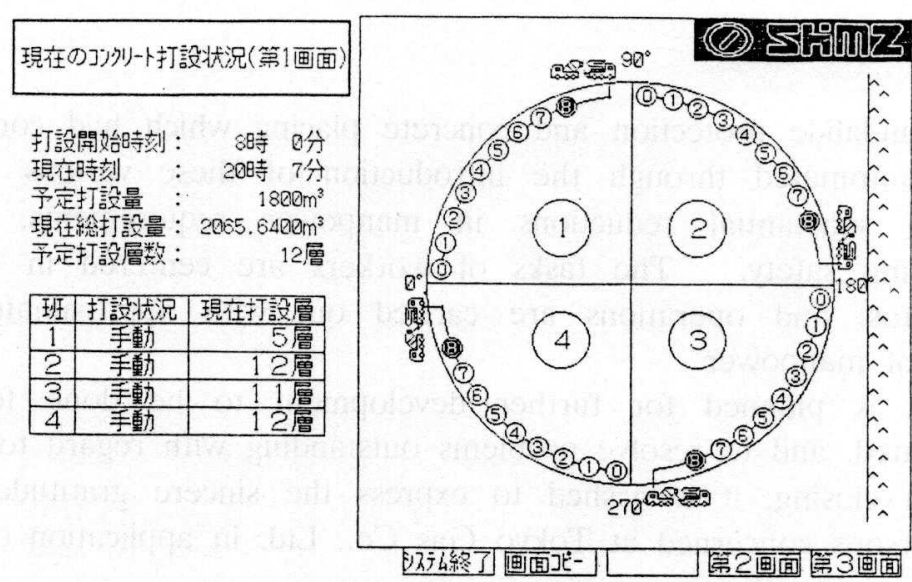

Fig.14-1 CONDITION OF CONCRETE PLACING

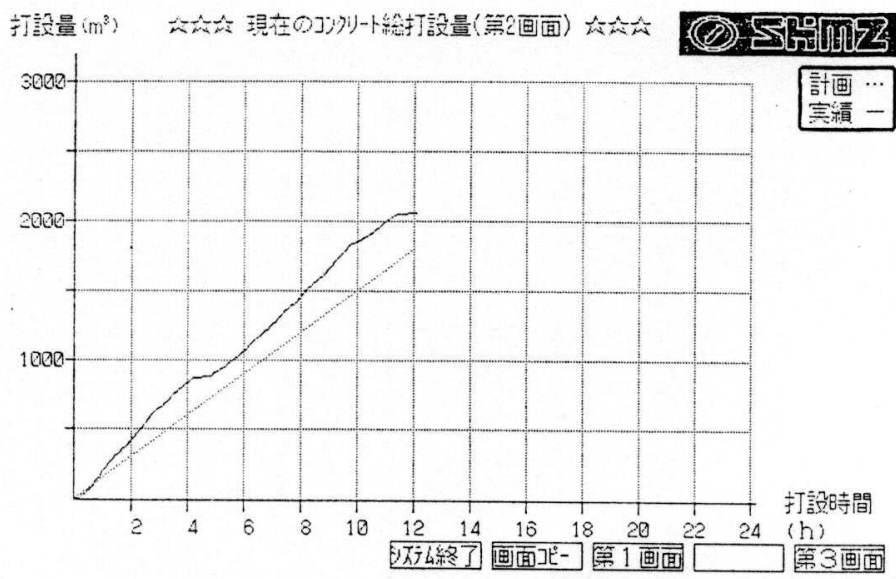

Fig.14-2 THE TOTAL VOLUME OF CONCRETE PLACED

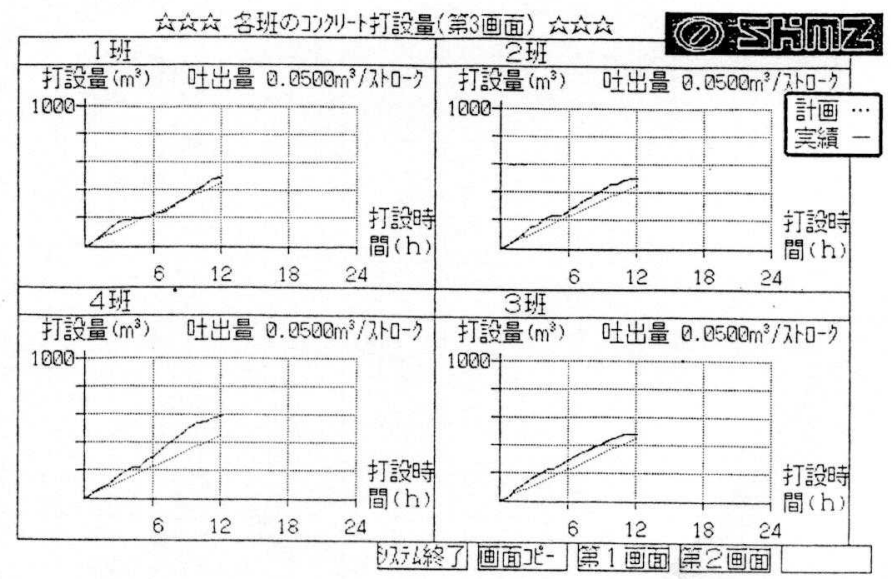

Fig.14-3 THE TOTAL OF VOLUME CONCRETE PLACED (FOR 4 CREWS) 
- Workers can be relieved of hard work such as compaction of concrete for long hours in confined space inside forms and carrying around of heavy vibrators for improvement of the work environment.

- Concrete of high quality can be placed because of accuracy of concrete placement volume due to automatic control, and appropriate compaction operations.

- By simply monitoring images of the placing management system, the state of concrete placing and quantity placed can be grasped so that construction can be done smoothly at all times.

\section{CONCLUSION}

Landalide protection and concrete placing which had conventionally relied on manual labor have been automated through the introduction of these various systems, and it has been succeeded in making substantial reductions in manpower requirements, executing work of high quarity, and enhancing safety. The tasks of workers are centered in monitoring of systems and operating of apparatus, and operations are carried out with approximately one-third to one-fourth of previous levels of manpower.

It is planned for further development to be done for processes which have not yet been automated, and to resolve problems outstanding with regard to conventional operations.

In closing, it is wished to express the sincere gratitude of the authors for the cooperation of the persons concerned at Tokyo Gas Co., Ltd. in application of the system to actual constructions. 